Technical Reports

\title{
Report on the Evaluation of Ugua J2 and J3 Reservoir Performance
}

\author{
${ }^{1}$ Okotie Sylvester, ${ }^{2}$ Ikporo Bibobra and ${ }^{3}$ Ovuema Augustina \\ ${ }^{1,3}$ Department of Petroleum and Gas Engineering, Federal University of Petroleum Resources, Effurun, Nigeria \\ ${ }^{2}$ Department of Chemical and Petroleum, Niger Delta University, Amasoma, Nigeria
}

Article history

Received: 09-02-2015

Revised: 02-03-2015

Accepted: 06-10-2015

Corresponding Author:

Okotie Sylvester

Department of Petroleum and Gas

Engineering, Federal University of

Petroleum Resources, Effurun,

Nigeria

Email: sterz_ok@yahoo.co.uk

\begin{abstract}
Globally, there are different techniques applied in the industry such as analog, volumetric, decline curve, material balance and simulation methods to estimate hydrocarbon reserves which depends upon the volume and quality of available data with some levels of uncertainties. The analogy method is applied by comparing factors for the current fields or wells while the volumetric method implies the determination of the extent of the reservoir, pore volume of the reservoir rock and the content of fluid within the reservoir pore volume when production and pressure data from field become available, decline curve analysis and material balance calculations become the predominant methods of calculating reserves since the hydrocarbon reserve estimates is a continuous process for a field that is producing. This study presents a report on the material analysis of Ugua J2 and J3 reservoirs with MBAL prior to the field's dynamic reservoir simulation. The available data were validated and the analytical plot of pressure and production data indicated that $\mathrm{J} 2$ and $\mathrm{J} 3$ reservoirs are communicating. Hence multi-tank material balance analysis approach linked with transmissibility was adopted to model the reservoirs. The Hurst-Van Everdingen radial aquifer model was selected as the most likely case. The oil initially in place value obtained for J2 and $\mathrm{J} 3$ are 125.006 and 80.689 MMstb.
\end{abstract}

Keywords: Hydrocarbon Reserves, Material Balance, MBAL, Communication, Data Quality Check, Transmissibility

\section{Introduction}

The process of estimating oil and gas reserves for a producing field starts from discovery and then continues in the entire life of the field and at each stage, there are different techniques applied depending upon the volume and quality of available data (SPEE, 1998). At the initial stage of field development, analog and volumetric methods are used to estimate oil and gas reserves which do not give a feel of the behaviour of the reservoir. The analogy method is applied by comparing factors for the current fields or wells while the volumetric method implies the determination of the extent of the reservoir, pore volume of the reservoir rock and the content of fluid within the reservoir pore volume (Petrobjects, 2003). The volumetric technique provides an estimate of the amount of hydrocarbons-in-place with inherent uncertainties in the input parameters such as porosity, saturation, formation volume factor and the bulk volume from geology. Ahmed (2010) stated that a proper averaging of saturation and porosity data is required. In addition, we should note that all reserve estimates involve some degree of uncertainty or probability distribution, depending mainly on the amount of reliable data but can be reduced within reasonable engineering tolerance of error. Practically, in the industry, a particular cut off is used on some of these parameters with the rational that; though the reservoir is porous but not all pore spaces are connected. This value varies among companies and is applied to account for the fraction not connected. Some companies carry out core-log comparison for quality control and assurance of petrophysical properties. The reservoir sand needs to be evaluated to determine the net-gross ratio to account for the shale sand since some of the reservoirs are not completely sand.

When production and pressure data from a field become available, decline curve analysis and material balance calculations become the methods of calculating reserves. These methods greatly reduce the uncertainty 
in reserves estimates; however, during early depletion, caution should be exercised in using them. Decline curve relationships are empirical and rely on uniform, lengthy production periods. Warner et al. (1979) stated that the material balance method has some limitations though can be used as a pre-processing tool to infer fluid in place, drive mechanisms and identify aquifer for a more sophisticated tool "reservoir simulation" which gives insight into dynamic rock and fluid properties for evaluation of past reservoir performance, prediction of future reservoir performance and reserve estimation. Besides, the significant different between MBE results and volumetric is usually overemphasized.

It therefore means that one of the fundamental challenges before the geophysicists, reservoir engineers and geologists is the ability for this integrated team to work harmoniously to obtain a near-exact value of the oil in place before field development and optimization start. Hence, a clear understanding of the reservoir is critical to the success of a field development program. This understanding must be developed through the application of an integrated work flow. In the ongoing research on workflow for reservoir study and challenges by Okotie et al. (2015) they presented a step by step approach and data require at each stage to assist new reservoir simulation engineers to successfully perform a field study. Prior to running the dynamic model; while build the simulation model, a simulation pre-processing such as PVT Analysis, Core/SCAL Analysis, VLP Curve generation, Production amd Events, Material balance and Decline Curve Analysis etc. is required. Hence, this study presents a material balance analysis report of Ugua $\mathrm{J} 2$ and $\mathrm{J} 3$ reservoirs, a field in the Niger Delta region of Nigeria.

\section{Material Balance Concept of Reserve Estimate}

Material Balance Equation (MBE) tool is used to interpret and predict reservoir performance. REPAT developed by author or MBAL by Petroleum expert can be used for the material balance analysis. It uses analytical method, a non-linear regression approach based on reservoir pressure decline against cumulative production. Odeh and Havlena (1963) rearrange MBE into different linear forms (Equation 2). This method requires the plotting of a variable group against another variable group selected depending on the reservoir drive mechanism and if linear relationship does not exist, then this deviation suggests that reservoir is not performing as anticipated and other mechanisms are involved which were not accounted for; but once linearity has been achieved, based on matching pressure and production data then a mathematical model has been achieved. This technique is referred to as history matching. Therefore, the application of the model enables predictions of the future reservoir performance.

The general material balance equation is given as Equation 1:

$$
\begin{aligned}
& N_{p} B_{o}+\left(G_{p}-N_{p} R_{s}\right) B_{g}
\end{aligned}
$$

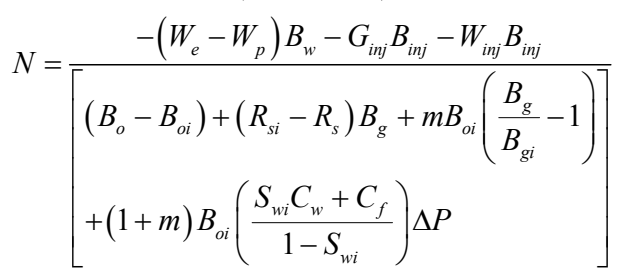

The straight line form of the material balance equation is given as:

$F=N\left\lfloor E_{o}+m E_{g}+E_{f, w}\right\rfloor+W_{e} B_{w}$

Where Equation 3 to 6 :

$E_{o}=\left(B_{o}-B_{o i}\right)+\left(R_{s i}-R_{s}\right) B_{g}$

$E_{g}=B_{o i}\left(\frac{B_{g}}{B_{g i}}-1\right)$

$E_{f, w}=(1+m) B_{o i}\left(\frac{S_{w i} C_{w}+C_{f}}{1-S_{w i}}\right) \Delta P$

$F=N_{p} B_{o}+\left(G_{p}-N_{p} R_{s}\right) B_{g}-W_{p} B_{w}$

Material balance analysis was carried out on Ugua J2 and J3 reservoirs. The Material Balance Analysis tool, MBAL, of Petroleum Experts Limited was used for the analysis. The reservoir pressure, PVT and production data, after careful review, served as input data into the MBAL program. Available geological maps and petrophysical data aided the estimation of the aerial extent of the reservoir and the aquifer. The in-place volumes acquired from the study are subject to validation by static and dynamic simulation. The workflow is given in Fig. 1.

\section{Data Quality Control and Quality Assurance}

Data QA/QC was performed to ascertain the quality of the data to be used for the project and to provide preliminary data validation that is to validate the allocated and the flow test data. Analytical plot of pressure and production with Microsoft excel was used to check for communication across the $\mathrm{J} 2$ and $\mathrm{J} 3$ reservoirs (Fig. 2). The samples for Ugua J2 and J3 reservoirs were validated through their opening pressures and saturation pressure for quality control of samples. 
Sometimes the measured value can be incorrect but a consistency check was performed before starting the tuning process which is almost impossible to match everything perfectly. It is worthy to not that when performing the PVT analysis, one of the experiments may worsen the others. Prior to fitting an Equation of State (EOS) model to the laboratory data, adjustments were made to the Differential Liberation formation volume factor and solution Gas oil ratio data to the reported separator conditions. Hence, before starting any study, all the available data should be assessed and any data discrepancies and/or deficiencies should be identified. The data requirements should be consistent with the objectives of the study.

\section{PVT Data}

The PVT analysis for Akpet GT9 and GT12 reservoir has been carried out. This is in line with fitting an Equation Of State (EOS) to the laboratory PVT experimental data and then using the EOS to produce ECLIPSE black oil PVT tables and EOS model for use in dynamic modeling of the Akpet reservoir dynamic simulation. Laboratory PVT Data reports were made available for the analysis. In GT9 and GT12 reservoirs, a total of twelve (12) components were defined in the characterization; eight (8) pure light hydrocarbons (from $\mathrm{C} 1$ to C6), two non-hydrocarbons $\left(\mathrm{N}_{2}\right.$ and $\left.\mathrm{CO}_{2}\right)$ and heavy components lumped as $\mathrm{C} 7+$ fraction. The $\mathrm{C} 7+$ of GT9 is characterized with a mole weight of 205.74 and specific gravity of 0.83184 respectively While GT12 is characterized with a mole weight of 212.72 and specific gravity of 0.834944 respectively. Table 2 shows the fluid composition of the surface recombined fluid sample. Detail analyses of the PVT results are not report in this study.

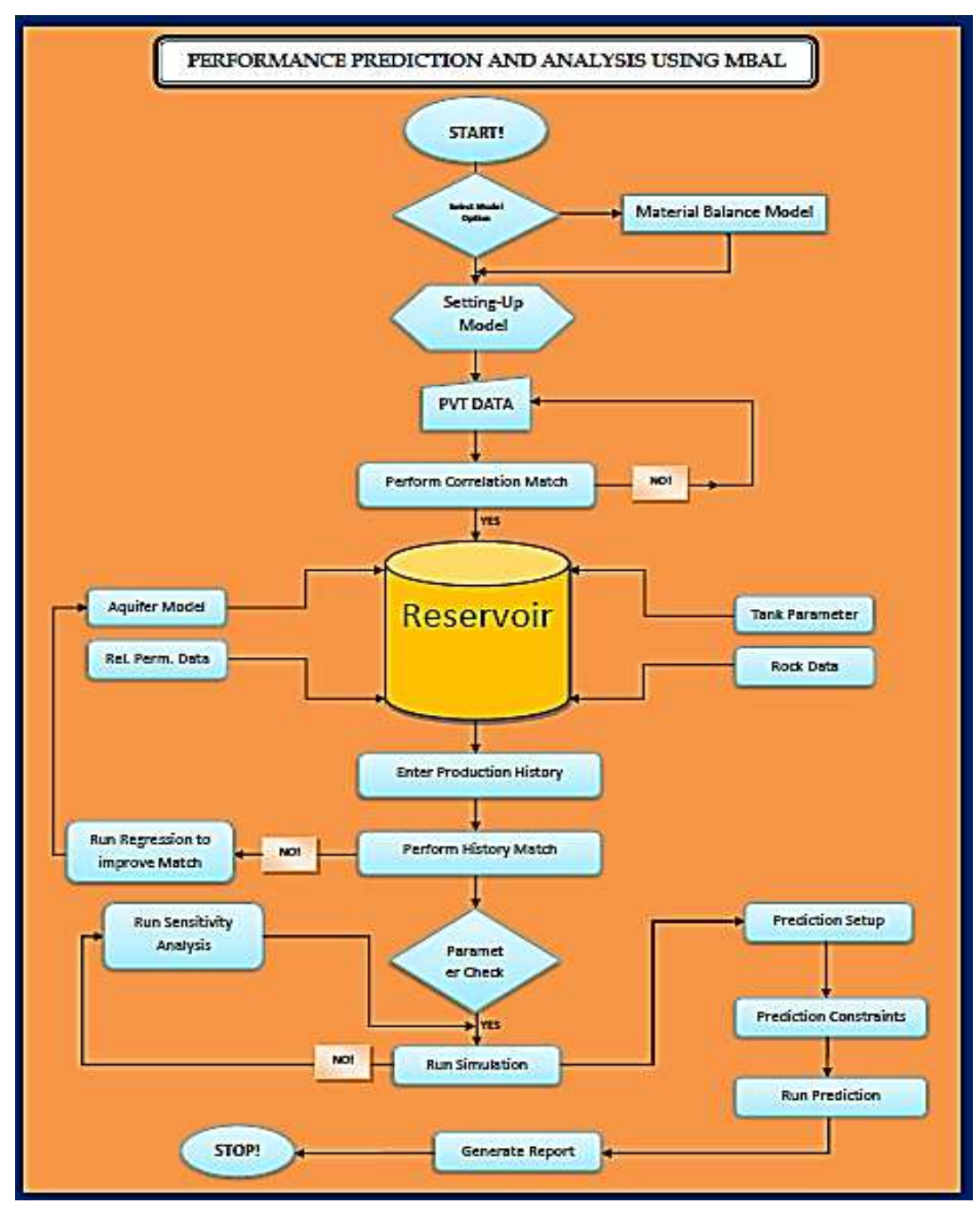

Fig. 1. MBAL workflow 


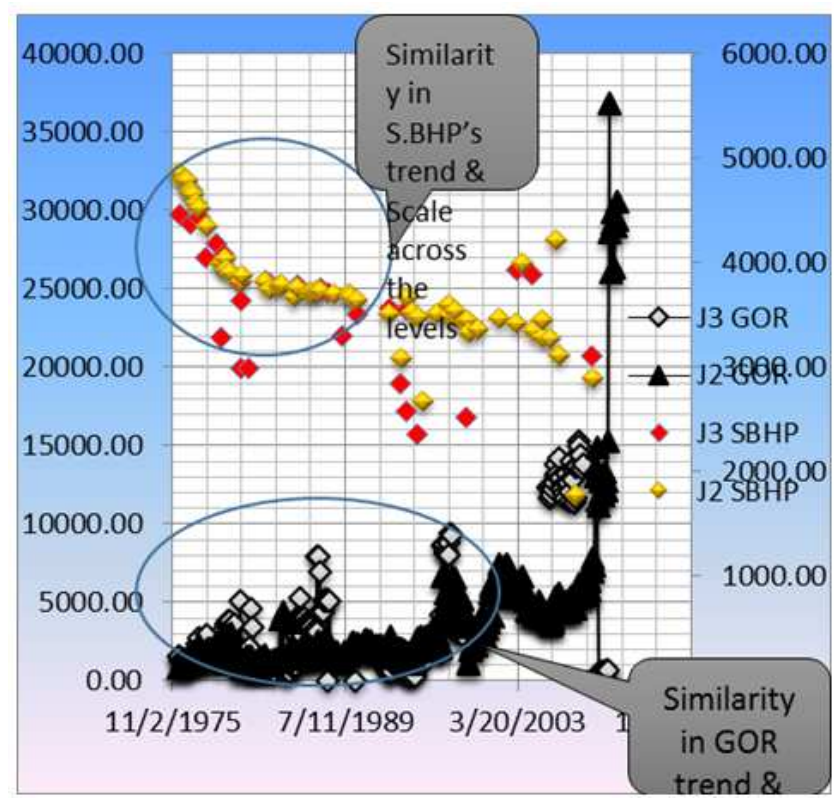

Fig. 2. GOR and SBHP Plots

Table 1. Ugua J2 and J3 reservoir PVT Data

\begin{tabular}{|c|c|c|c|}
\hline \multicolumn{2}{|l|}{ J2 Reservoir } & \multicolumn{2}{|l|}{ J3 Reservoir } \\
\hline Property & Value & Property & Value \\
\hline Formation GOR (scf/STB) & 1736.000 & Formation GOR (scf/STB) & 1253.000 \\
\hline Oil gravity & 34.800 & Oil gravity & 33.700 \\
\hline Gas Gravity & 0.863 & Gas Gravity & 0.698 \\
\hline Mole Percent H2S (\%) & 0.000 & Mole Percent H2S (\%) & 0.000 \\
\hline Mole Percent CO (\%) & 1.840 & Mole Percent CO (\%) & 2.750 \\
\hline Mole Percent N2 (\%) & 1.090 & Mole Percent N2 (\%) & 0.070 \\
\hline Water Salinity (ppm) & 10000.000 & Water Salinity (ppm) & 10000.000 \\
\hline $\mathrm{Pb}, \mathrm{Rs}$, Bo correlation & Lasater (1958) & Pb, Rs, Bo Correlation & Glaso (1980) \\
\hline Oil Viscosity correlation & Petrosky and Farshad (1993) & Oil Viscosity Correlation & Beal (1946) \\
\hline Separator & Single stage & Separator & Single Stage \\
\hline J2 Reservoir & & J3 Reservoir & \\
\hline Parameter & Value & Parameter & Value \\
\hline Temperature (deg.F) & 229.00 & Temperature (deg.F) & 228.00 \\
\hline Initial Pressure (psi) & 4718.00 & Initial Pressure (psi) & 4711.29 \\
\hline Porosity & 0.15 & Porosity & 0.15 \\
\hline Connate Water Saturation & 0.15 & Connate Water Saturation & 0.15 \\
\hline Water Compressibility (1/psi) & Use correlation & Water Compressibility (1/psi) & Use correlation \\
\hline Initial Gas Cap & 0.038 & Initial Gas Cap & 0.116 \\
\hline
\end{tabular}

\section{Hydraulic Communication Check}

Analytical plots of the pressure and the production data as shown in Fig. 2 have been used to check for a possible communication across the $\mathrm{J} 2$ and $\mathrm{J} 3$ reservoir levels.

Similar SBHP and GOR trends for J2 and J3 reservoirs indicate possible communication across these levels, hence $\mathrm{J} 2$ and $\mathrm{J} 3$ was modeled as multiple tanks connected by means of a transmissibility.

\section{Data Presentation}

Ugua J2-J3 reservoirs are both saturated oil reservoir. J2 reservoir operates at a temperature of 229 deg. F and a bubble point of 4718 psi while J3 reservoir operates at a temperature of $228 \mathrm{deg}$. F and a bubble point 4711.29 psi. J2 reservoir production history spans a period of 35 years (May 1976-January 2011) while J3 spans a period of 34 years (February 
1977-January 2011). The PVT and reservoir (tank) data used in the analysis for both reservoirs are as shown in the Table 1 and 2.

\section{Procedure}

The Havlena-Odeh and the F/Et Vs. We/Et straight line plots of the graphical method incorporating various radial aquifer models were used to evaluate the aquifer properties, match the reservoir pressure and determine the Gas Initially In-Place (GIIP). The accuracy of the results was validated with the history match of the model's pressure and production.

The analysis procedure is as follows:

- Pressure and production data is entered on a Tank basis

- The matching facility in MBAL is used to adjust the empirical fluid property correlations to fit measured PVT laboratory data. Correlations are modified using a non-linear regression technique to best fit the measured data
- The graphical method plot is used to visually determine the different Reservoir and Aquifer parameters. The Havlena-Odeh and the F/Et Vs. We/Et straight-line plots of the graphical method were used to visually observe and determine the appropriate aquifer model and parameters

- The non-linear regression engine of the analytical method is used in estimating the unknown reservoir and aquifer parameters and fine tune the pressure and production match. This is done for various aquifer models and their standard deviations from the actual field data are compared

- The accuracy of the model is validated by history matching the field pressure and production data with the simulation data

\section{Results}

The summary of the result from the analysis is shown in Table 3.

The summary of the aquifer parameters used in the Material Balance calculations and the source of each data is depicted in Table 4 and 5.

Table 3. Summary of Ugua J2 and J3 reservoir analysis results

\begin{tabular}{lllr}
\hline J2 Reservoir & & J3 Reservoir & \\
\hline & Hurst-Van & Hurst-Van \\
everdingen-modified & Aquifer moder & 96.170 \\
Reservoir Thickness (m) & 282.000 & Reservoir Thickness (m) & 3576.000 \\
Reservoir Radius (m) & 5000.000 & Reservoir Radius (m) & 3.930 \\
Outer/Inner Radius & 2.560 & Outer/Inner Radius & 139.000 \\
Encroachment Angle & 224.000 & Encroachment Angle & 35.000 \\
Aquifer Permeability (md) & 2.480 & Aquifer Permeability (md) & 80.689 \\
OIIP (MMSTB) & 125.006 & OIIP (MMSTB) & 68.700 \\
GIIP (Bscf) & 42.720 & GIIP (Bscf) &
\end{tabular}

Table 4. Summary of input data for Ugua J2 reservoir aquifer model and transmissibility

\begin{tabular}{|c|c|c|}
\hline \multicolumn{3}{|l|}{ J2 Reservoir } \\
\hline Paramerter & Value & Source \\
\hline Aquifer permeability & 2.48000 & Regression in MBAL \\
\hline Encroachment Angle (deg.) & 224.00000 & Fault Polygon \\
\hline Reservoir Radius (m) & 5000.00000 & Estimation from seismic map \\
\hline Outer/Inner radius (Ratio) & 2.56000 & Estimation from seismic map \\
\hline Reservoir Thickness (m) & 282.00000 & Logs \\
\hline Transmissibility $(\mathrm{Rb} /$ day*cp/psi) & 4.76925 & Regression in MBAL \\
\hline \multicolumn{3}{|l|}{ J3 Reservoir } \\
\hline Paramerter & Value & Source \\
\hline Aquifer permeability & 35.00000 & Regression in MBAL \\
\hline Encroachment Angle (deg.) & 139.00000 & Fault Polygon \\
\hline Reservoir Radius (m) & 3576.00000 & Estimation from seismic map \\
\hline Outer/Inner radius (Ratio) & 3.93000 & Estimation from seismic map \\
\hline Reservoir Thickness (m) & 96.70000 & Logs \\
\hline Transmissibility $(\mathrm{Rb} /$ day*cp/psi) & 4.76925 & Regression in MBAL \\
\hline
\end{tabular}




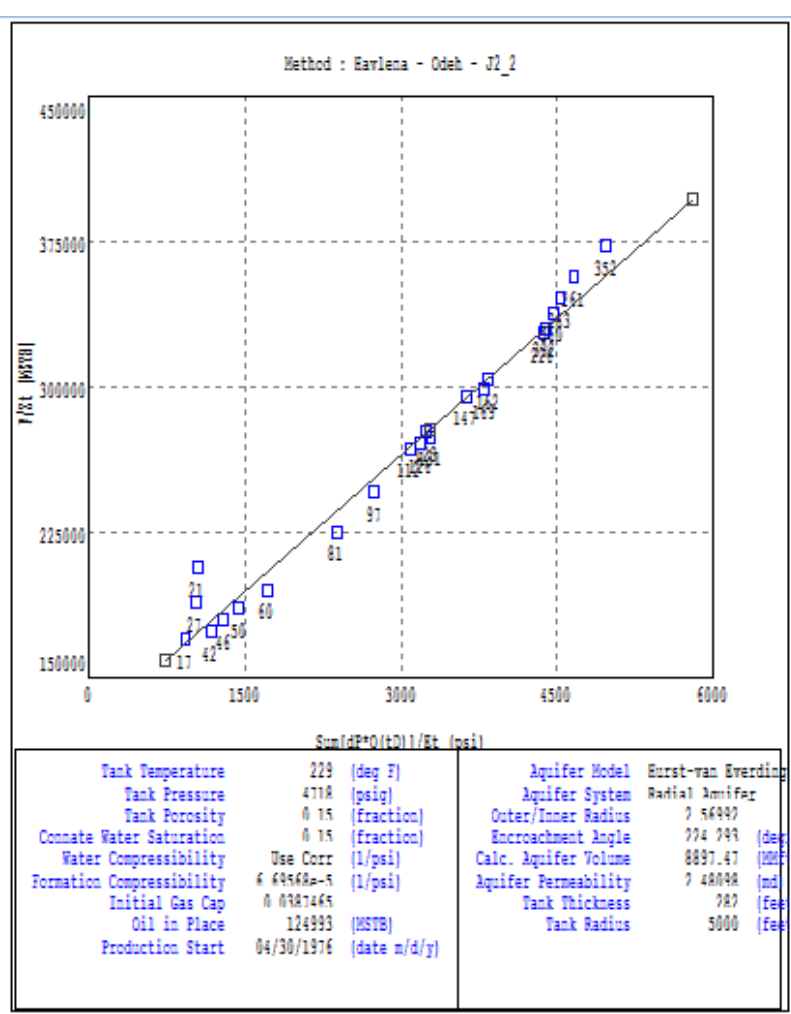

Fig. 3. J2 Reservoir graphical diagnostic plot

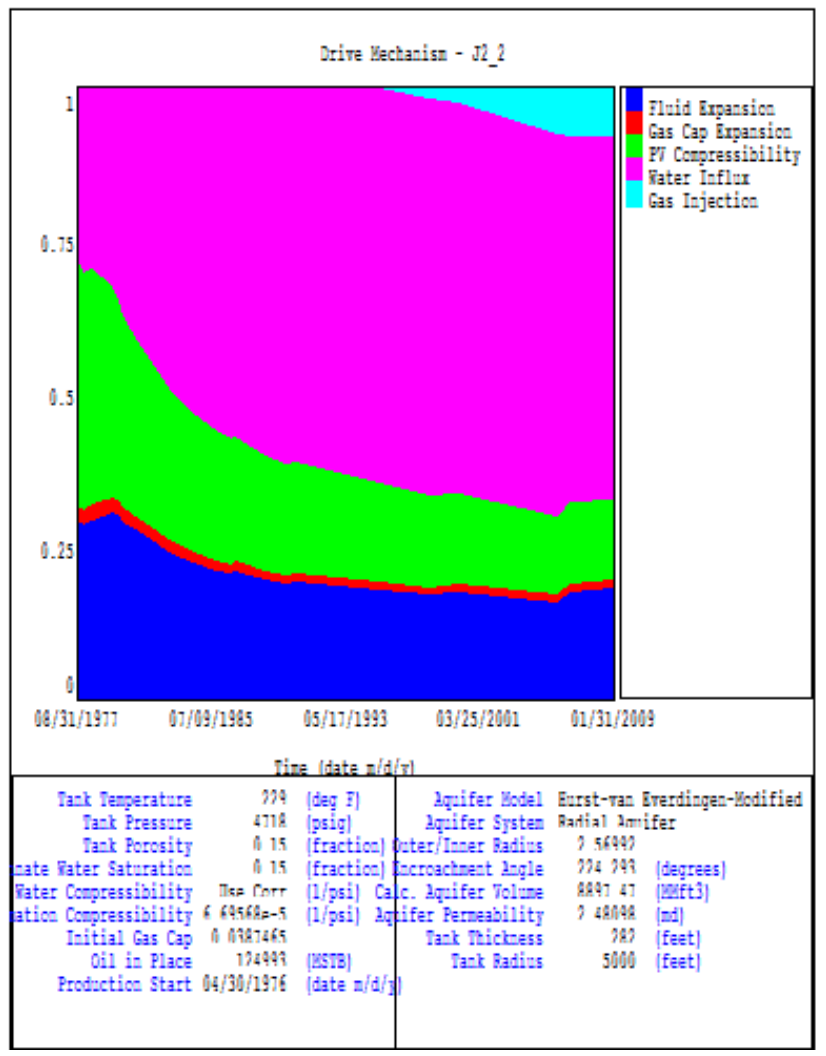

Fig. 4. J2 reservoir energy plot 


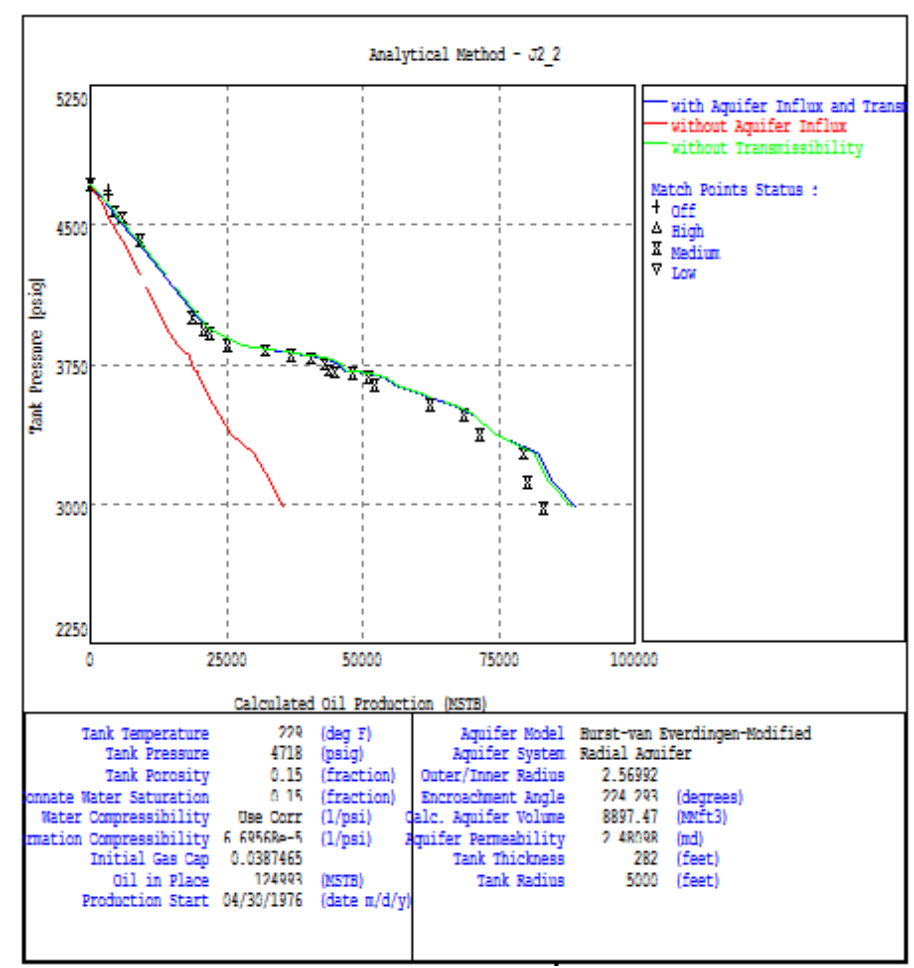

Fig. 5. J2 reservoir analytical plot

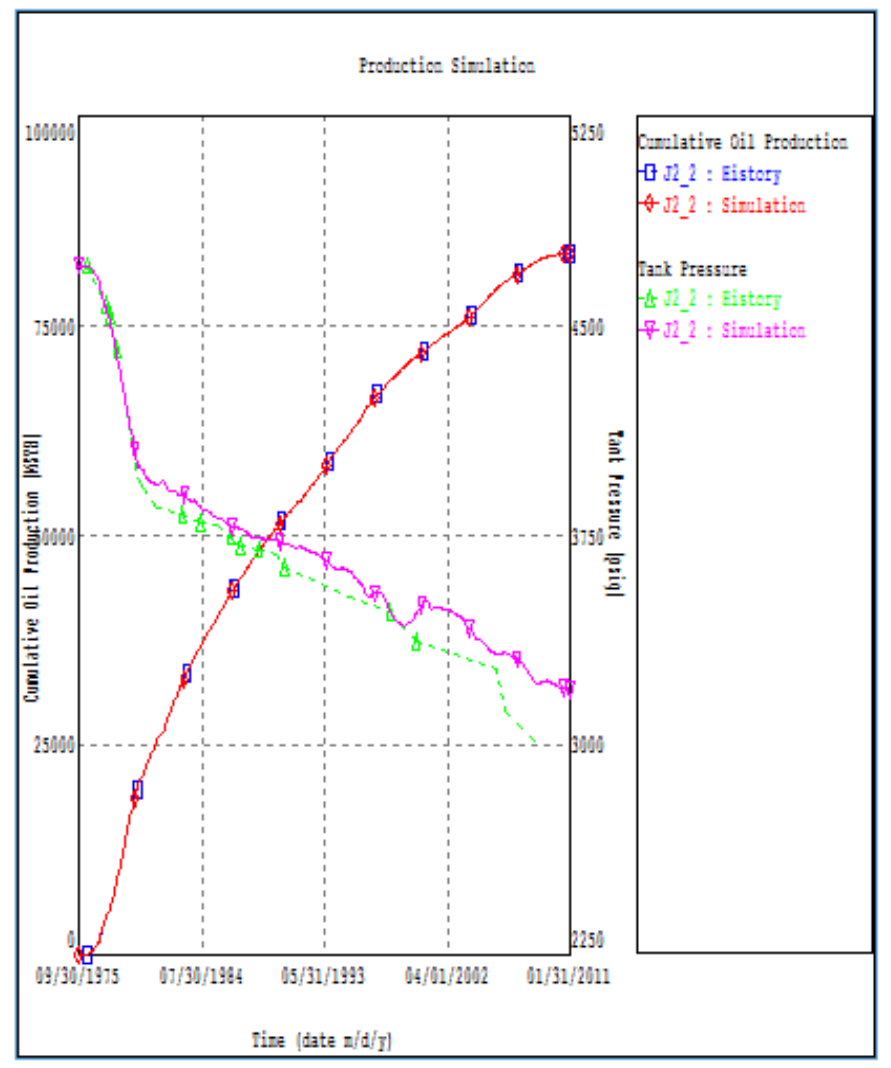

Fig. 6. J2 reservoir pressure history match plot 


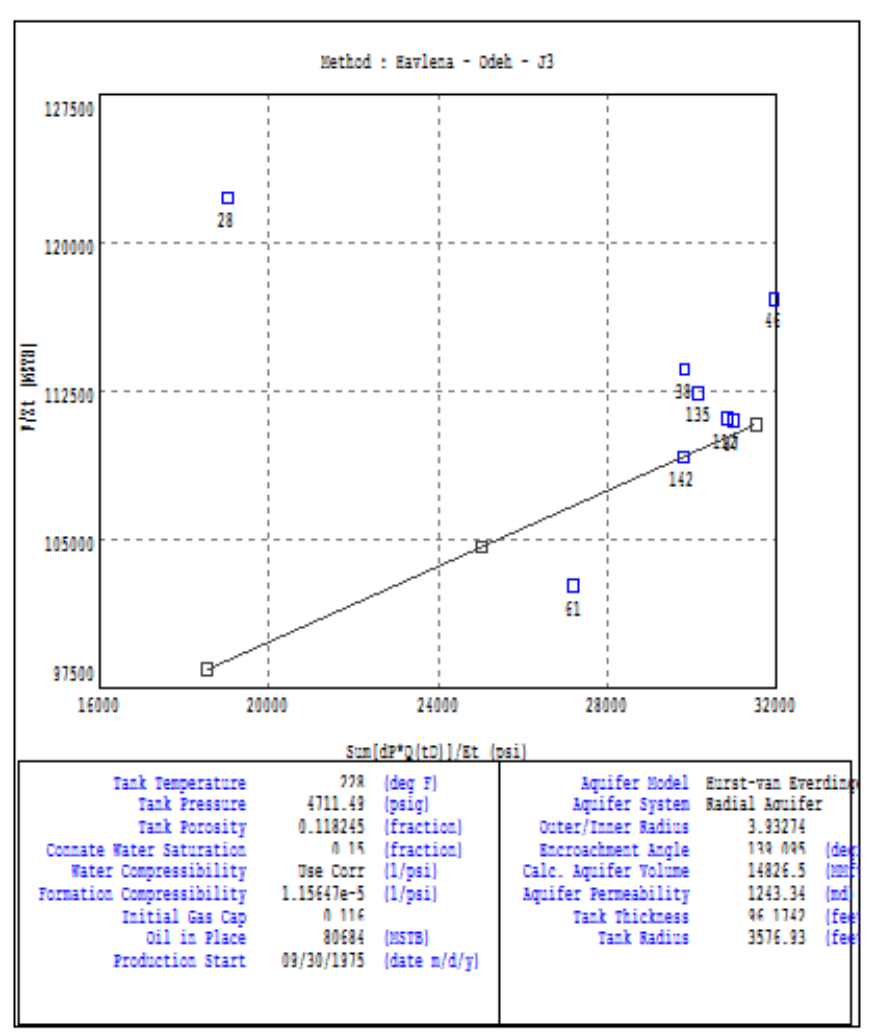

Fig. 7. J3 reservoir graphical plot

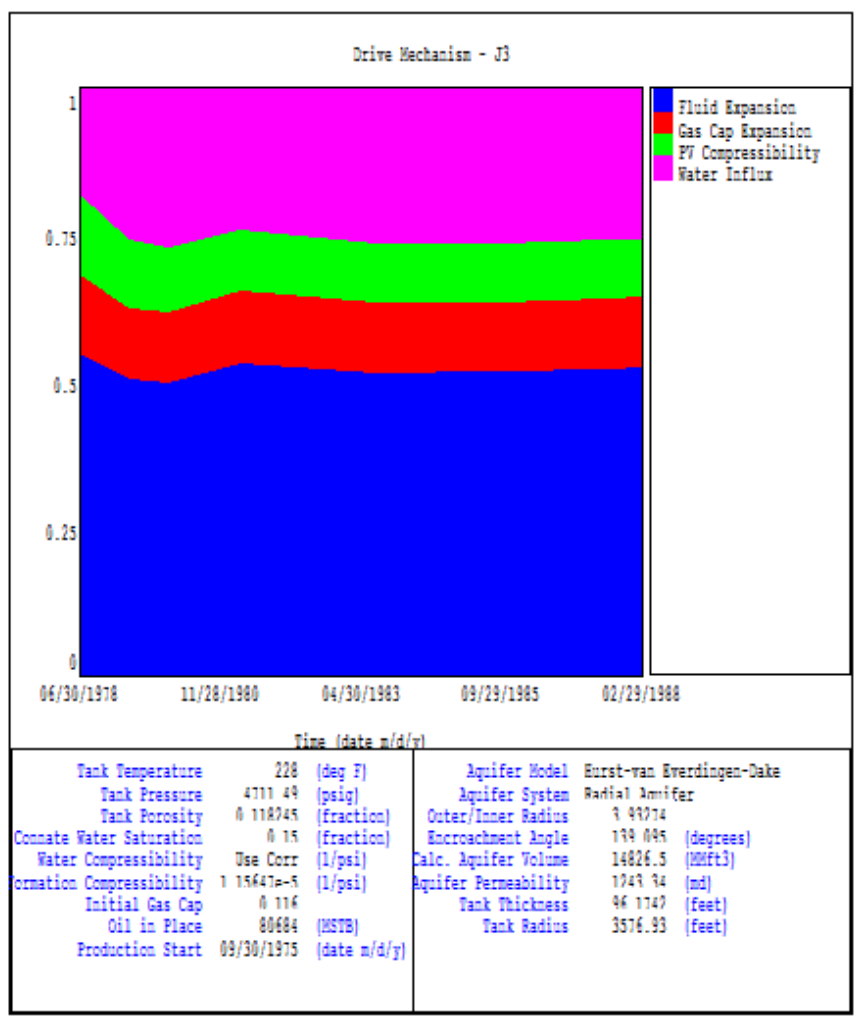

Fig. 8. J3 reservoir energy plot 


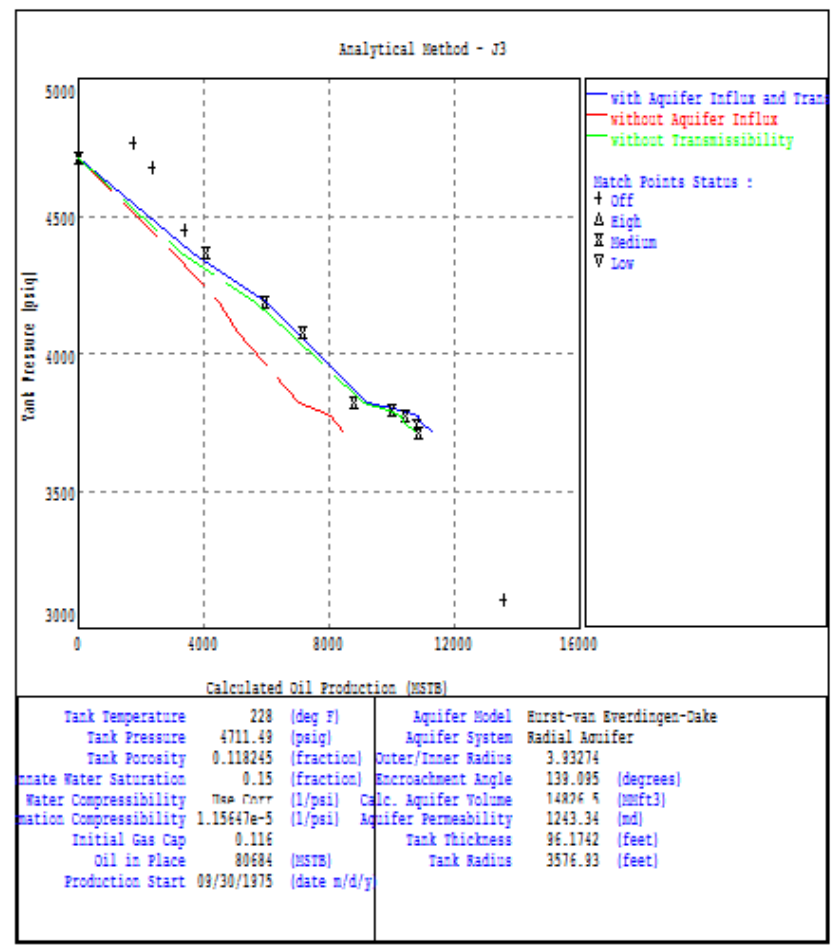

Fig. 9. J3 reservoir analytical plot

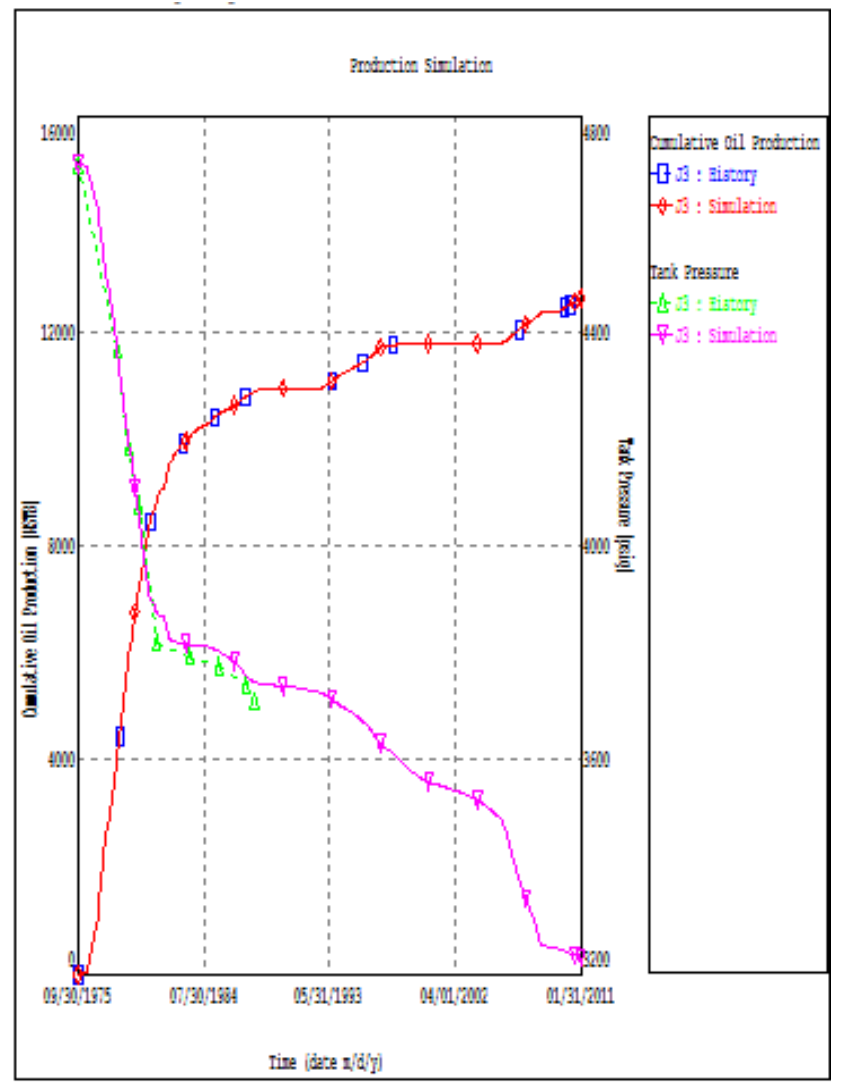

Fig. 10. J3 reservoir analytical plot 


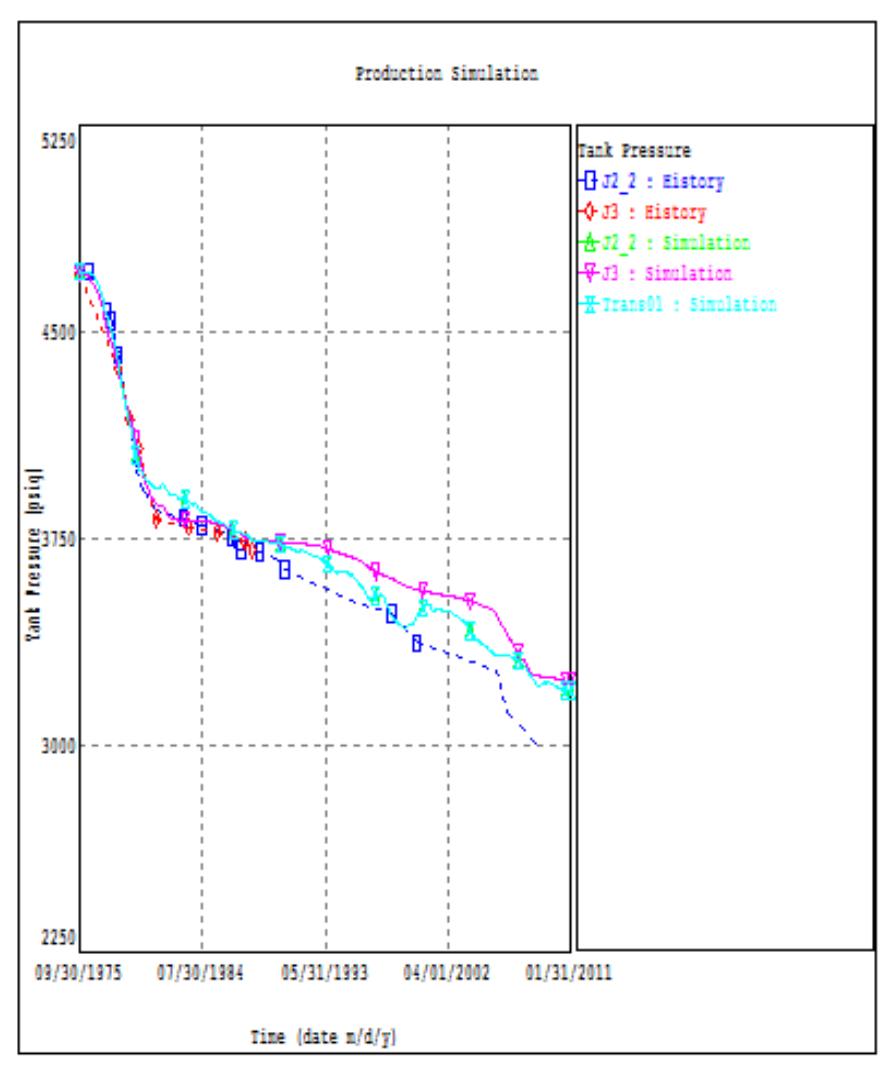

Fig. 11. J3 and J3 reservoirs pressure plot with a transmissibility

The Hurst-Van Everdingen Modified model was selected as the most likely case for J2 while Hurst-Van Everdingen-Dake for J3. The parameters used to obtain the history match and the OIIP from both models with the Hurst-Van Everdingen Modified and Hurst-Van Everdingen radial aquifer compare favorably with the expected values. The plots generated from the most likely case models are shown in Fig. 3-11.

\section{Constraints}

- Unknown aquifer characteristics and properties

\section{Inference from Analysis}

Inferences from the Material Balance analysis of the Ugua J2 reservoir are as follows:

- The OOIP is $125.006 \mathrm{MMstb}$

- The most likely aquifer model is the Hurst-Van Everdingen Modified radial aquifer

- The reservoir is supported by a combined drive majorly of water influx, fluid expansion and gas injection mechanisms

Inferences from the Material Balance analysis of the Ugua J3 reservoir are as follows:
- The OOIP is $80.689 \mathrm{MMstb}$

- The most likely aquifer model is the Hurst-Van Everdingen-Dake radial aquifer

- The reservoir is supported by a combined drive majorly of fluid expansion and water influx with a minimal gas cap expansion mechanisms

- It can be established there is communication between $\mathrm{J} 2$ and $\mathrm{J} 3$ as can be seen from the combined history match pressure and transmissibility plot of Fig. 11

\section{Conclusion}

From the hydraulic communication check performed given in Fig. 2, we suspect communication between J2 and J3 reservoirs, hence multi-tank material balance analysis approach linked with transmissibility was adopted to model the reservoirs. The results obtained will be used in the full field Ugua reservoir simulation study and the oil initially in place volume will be validated with the static and dynamic models. The HurstVan Everdingen radial aquifer model was selected as the most likely case.

The summary of the results from the material balance analysis of the Ugua J2 and J3 reservoir levels is depicted in the Table 6 . 
Table 6. Ugua J2 and J3 material balance results

\begin{tabular}{lllll}
\hline Resevoir level & OIIP $($ MMstb) & GIIP $($ Bscf) & Available drive mechanism & Likely aquifer \\
\hline $\mathrm{J} 2$ & 125.006 & 42.72 & Combination drive & Hurst-Van Everdigen-Modified \\
$\mathrm{J} 3$ & 80.689 & 68.70 & Combination drive & Hurst-Van Everdigen-Dake \\
\hline
\end{tabular}

\section{Acknowledgment}

The authors gratefully appreciate the management and staff Lenswell Service Nigeria Limited for providing the data, support and permission to publish this work and also the anonymous reviewers and the editor for their valuable comments and insightful suggestions to improve this study.

\section{Funding Information}

The Federal University of Petroleum Resources, Department of Petroleum and Natural Gas Engineering.

\section{Author's Contributions}

Okotie Sylvester: Participated in the data QA/QC, hydraulic communication check, development of study methodology, model build with MBal and contributed to the writing of the manuscript.

Ikporo Bibobra: Participated in the collection of data, PVT model, result analysis and contributed to the writing of the manuscript.

Ovuema Augustina: Participated in the collection of data, result analysis and contributed to the writing of the manuscript.

\section{Ethics}

This article is original and contains unpublished material. The corresponding author confirms that all of the other authors have read and approved the manuscript and no ethical issues involved.

\section{References}

Ahmed, T., 2010. Reservoir Engineering Handbook. 4th Edn., Gulf Professional Publishing, Amsterdam, ISBN-10: 0080966675, pp: 1472.

Beal, C. 1946. The viscosity of air, water, natural gas, crude oils and its associated gases at oil field temperatures and pressures. Trans. AIME, 165: 94-112.

Glaso, O., 1980. Generalized pressure-volumetemperature correlations. JPT, 32: 785-795.

Lasater, J.A., 1958. Bubble point pressure correlation. Trans. AIME.

Odeh, A.S. and D. Havlena, 1963. The material balance as an equation of a straight line. J. Petroleum Technol., 15: 896-900. DOI: 10.2118/559-PA

Okotie, S. and B. Stanley, and B. Ikporo, 2015. Work flow for reservoir study and challenges. Proceedings of the Nigeria Annual International Conference and Exhibition, Aug. 4-6, SPE 178290, Lagos, Nigeria.

Petrobjects, 2003. Petroleum reserve estimation methods.

Petrosky, G.E., and F. Farshad, 1993. Pressure-volumetemperature correlations for Gulf of Mexico crude oils. Proceedings of the 68th Annual Technical Conference of the SPE in Houston, Oct. 3-6, Society of Petroleum Engineers, Texas.

SPEE, 1998. Oil and gas reserve evaluation. Monograph. Society of Petroleum Evaluation Engineers.

Warner, H.R., J.H. Hardy, N. Robertson and A.L. Barnes, 1979. University block 31 field study: Part 1-middle Devonian reservoir history match. J. Petroleum Technol., 31: 962-970. DOI: 10.2118/7468-PA 